\title{
About disappearance of a large Lake Ebi-Nur, Xinjiang, CHINA
}

\author{
Alexey Terekhov ${ }^{1,2^{*}}$, Nurlan Abayev ${ }^{2,3}$ \\ ${ }^{1}$ Institute of information and computing technology MES, Almaty, 050010, Kazakhstan \\ ${ }^{2}$ RSE Kazhydromet, Almaty, 050022, Kazakhstan \\ ${ }^{3}$ al-Farabi Kazakh National university, Almaty, 050040, Kazakhstan
}

\begin{abstract}
This research considers the process of degradation of the large, bitter-salty Lake Ebi-Nur, located in the Xinjiang (Northwest China), on the border with Kazakhstan. Satellite monitoring using LANDSAT-8 and SENTINEL-2 in recent years has shown the continuation of the process of rapid shallowing of this water body. The area of the lake water mirror decreased from $900 \mathrm{~km}^{2}$ in 2018 to $210 \mathrm{~km}^{2}$ in 2021 . The reasons for the degradation of Lake Ebi-Nur are the withdrawal of a significant amount of river's runoff for arable land irrigation, against the background of three (2019-2021) strongly low-water years. The stability of the water mirror area of Lake Ebi-Nur and the cultivation of over 600 thousand hectares of irrigated arable land in its basin is possible only with the alternation of low-water and high-water years. Three sharply low-water years in a row have brought the lake to a critical state. The continuation of low water in 2022, most likely, will transfer this lake to the state of a salt marsh. The degradation of Lake Ebi-Nur carries significant environmental risks. This lake is located in a natural area of very strong winds (Dzungarian Gate). The drained parts of lake's bottom become sources of salt storms in direction to agricultural lands and large settlements, including the capital of Xinjiang, city Urumqi. A definite solution to the problem may be the transfer of additional water resources to the Lake Eb-Nur basin from the neighboring water-surplus valleys of the Ili River or the Kara-Ertis River. However, these rivers are transboundary (China-Kazakhstan) and additional returnable seizures of their water resources to the Lake Ebi-Nur will be hard perceived in Kazakhstan.
\end{abstract}

\section{Introduction}

The bitter-salty Lake Ebi-Nur, located near the border with Kazakhstan on the territory of the Xinjiang Uygur Autonomous Region of China, is part of the Balkhash-Alakol group of lakes and occupies a last, southeastern position there, see Fig.1. The area of the lake is unstable and in the last 20 years has fluctuated between $500-900 \mathrm{~km}^{2}$ [1]. This water body is fed by rivers accumulating water from the Eastern Tien Shan ridges (Boro-Horo Ridge,

\footnotetext{
* Corresponding author: aterekhov1@yandex.ru
} 
Ukeng Ridge). The largest rivers of this lake basin are the Kuitun River and the Bolo-Tala River. The outflows of all these rivers are completely regulated. Part of the runoff is spent on the water supply of settlements, the largest of which is the city of Kuitun, with a population of over 300 thousand peoples. The other part goes to agricultural irrigation. The northern foothills of the Eastern Tien Shan belong to the southern border of the Dzungarian Plain, which is characterized by a hot climate and exceptional aridity. Crop production in this area is possible only with irrigation of arable land. In the Lake Ebi-Nur basin there are over 600 thousand hectares of arable land used for agricultural crops with moderate water consumption (cereals, cotton, etc.). To improve the water supply of the region, two water channels with a length of about $500 \mathrm{~km}$ each were carried out here, which transport water from the large transboundary (PRC-Kazakhstan-Russia) Irtysh River (in the territory of the China it is called the Black Irtysh) $[2,3]$. The water from these channels does not directly enter into Lake Ebi-Nur basin, but maintains the water supply of the adjacent basin of Lake Manas. This has a positive effect on the water supply of the entire district, since it has a common agricultural irrigation system. In Central Asia, in conditions of arid climate and lack of humidification, water availability of agricultural lands has a high priority, therefore, the low water content of the season primarily affects the state of final water bodies [4].

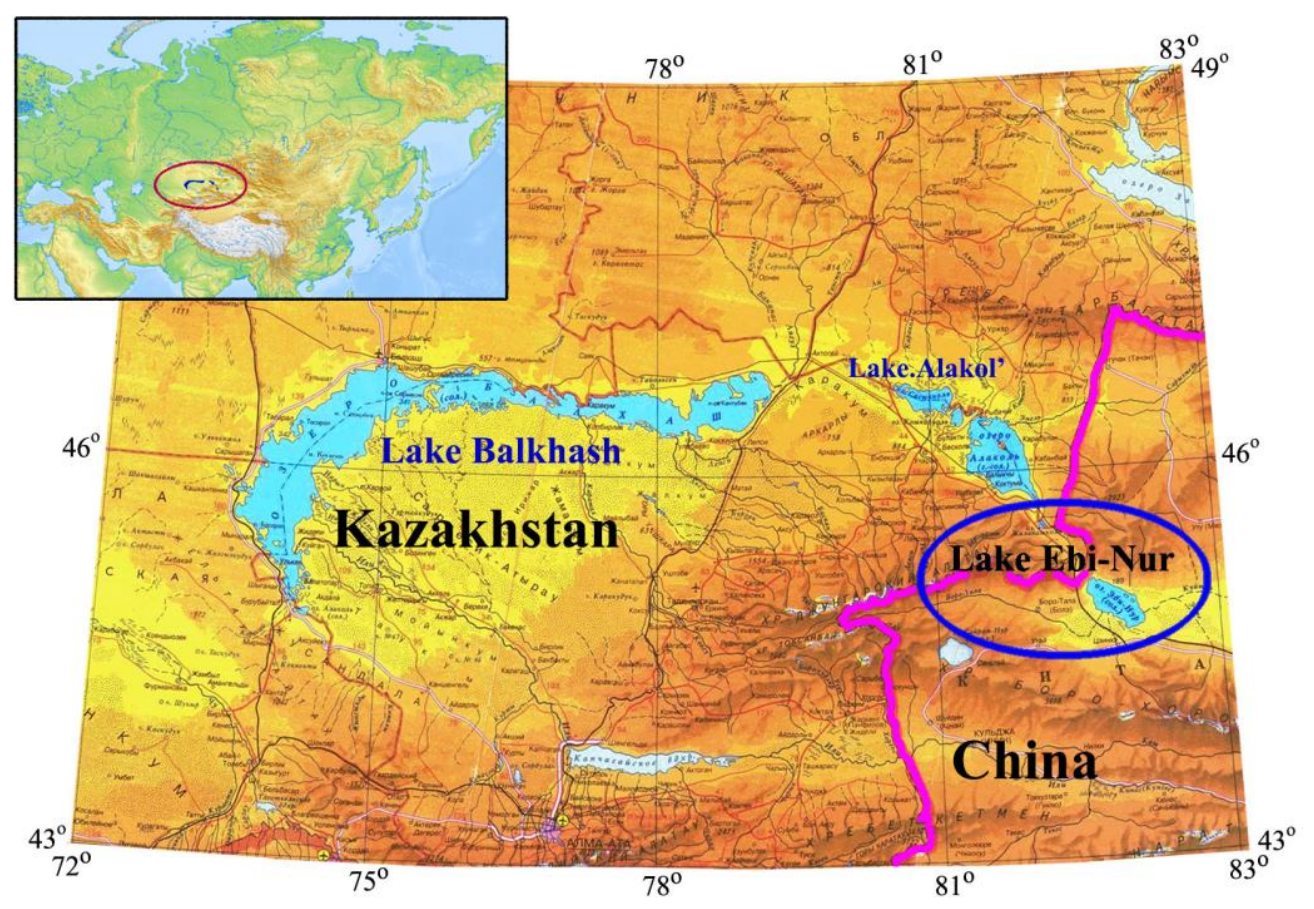

Fig.1. Disposition of Balkhash-Alakol's group of lakes

\section{Materials and methods}

Lake Ebi-Nur is located in an area characterized by very strong winds (Dzungarian Gate, up to $70 \mathrm{~m} / \mathrm{sec})$. The interaction of strong winds with the water mirror of the shallow lake 
formed a sandbar dividing the lake into two parts. The shallow northern part and the deeper southern part, see Fig.2.
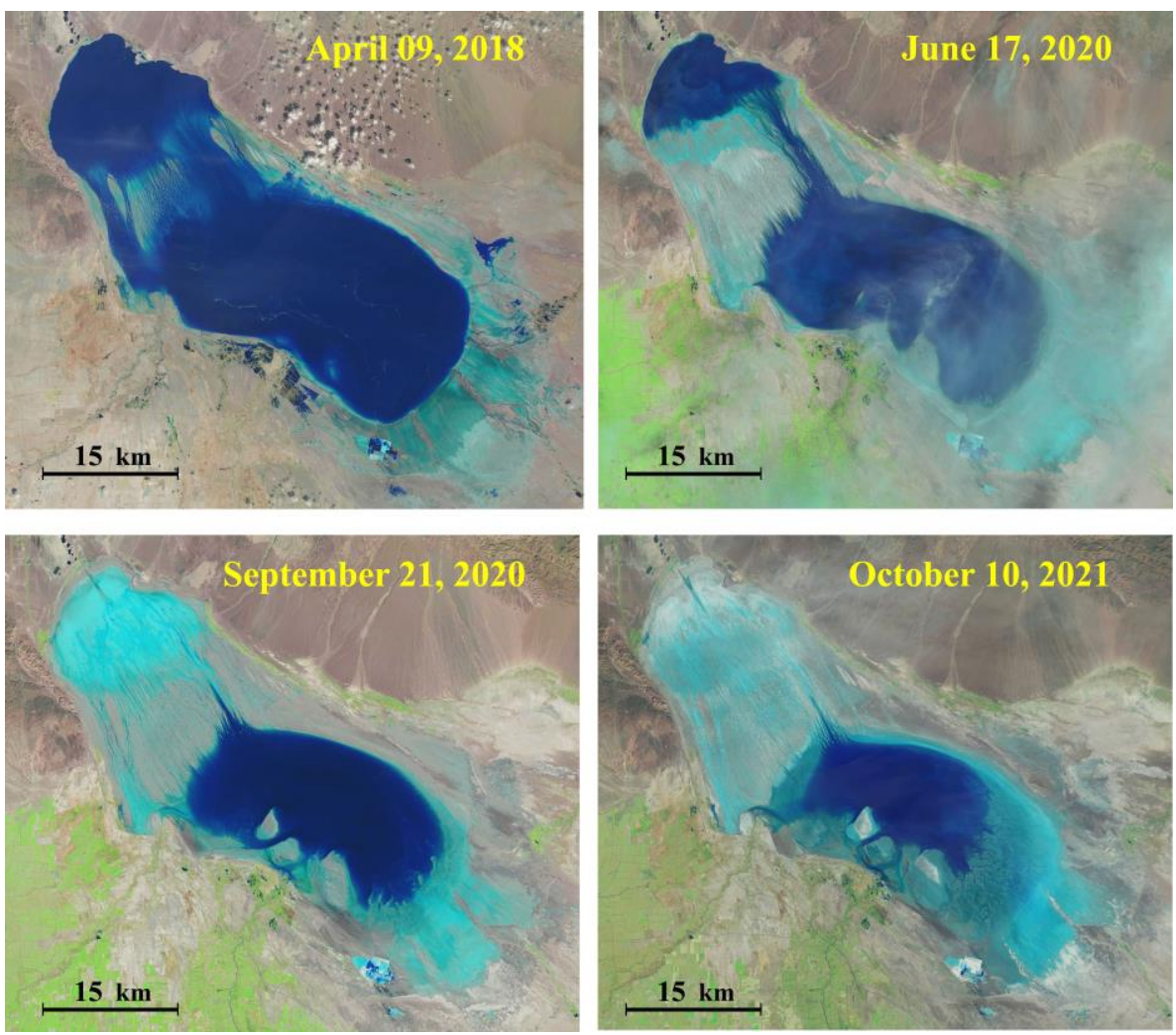

Fig.2. Landsat-8 images of Ebi-Nur Lake during last years. From GloVis (USGS) data portal

Drying up of the northern part of the Lake Ebi-Nur is an extremely unfavorable factor that creates serious risks to the ecology of the foothills of the Eastern Tien Shan. Very strong winds, typical in this area, creates salt storms from the dried-up northern part of the lake bottom. Salt storms carry significant amounts of salt over a distance of up to 100-200 km, which negatively affects the entire ecosystem of the territories adjacent to the lake from the east Lake Ebi-Nur [5], fig.3.

Satellite monitoring of the water mirror area of Lake Ebi-Nur with help LANDSAT and SENTINEL-2 images was carried out earlier [1]. In this study, one more year of observations (2021) was added to the available data. However, this year the condition of the lake has deteriorated dramatically and there is a threat of turning it into a salt marsh.

\section{Results and Discussion}

According to satellite monitoring (LANDSAT, SENTINEL-2A), the hot and low-water year 2020 led to a significant shallowing of Lake Ebi-Nur [1]. The area of its mirror fell to $340 \mathrm{~km}^{2}$, a value close to the multi-year minimum of the $1990-2020$ period of $339.3 \mathrm{~km}^{2}$ dated on September 20, 2014. The lack of water in 2021 lowered this value even lower, to $210 \mathrm{~km} 2$, which is the absolute historical minimum of the period of satellite observations 
(1989-2021), see Fig.4. The continuation of the low-water regime of the rivers of the Eastern Tien Shan in 2022 may transfer the vast majority of the remaining water body of Lake Ebi-Nur to the state of a salt marsh. The formation of a salt marsh is recognized on satellite imagery through the loss of a high spectral difference between the water mirror and land and the appearance of another intermediate spectral class, "not water", but also "not land". In the Landsat-8 image for October 10, 2021 (Fig. 2), a significant part of the lake bottom is already occupied by this new spectral class.

The long-term dynamics of weather regimes in the Central Asian region is characterized by a certain persistence, "long memory". The weather trends are maintained [6,7]. Therefore, there is an increased probability of continuation of the low-water regime in 2018-2021 and in the 2022 season. If the river's outflow in the 2022 season remains low, salt storms, that stopped at the end of the last century due to the flooding of the northern part of Lake Ebi-Nur, may resume in the region. The negative consequences of such a large-scale wind salt transport from the drained part of Lake Ebi-Nur bottom for the ecology of the region as a whole and for agricultural production in the Dzungarian plain are obvious, see Fig.3.
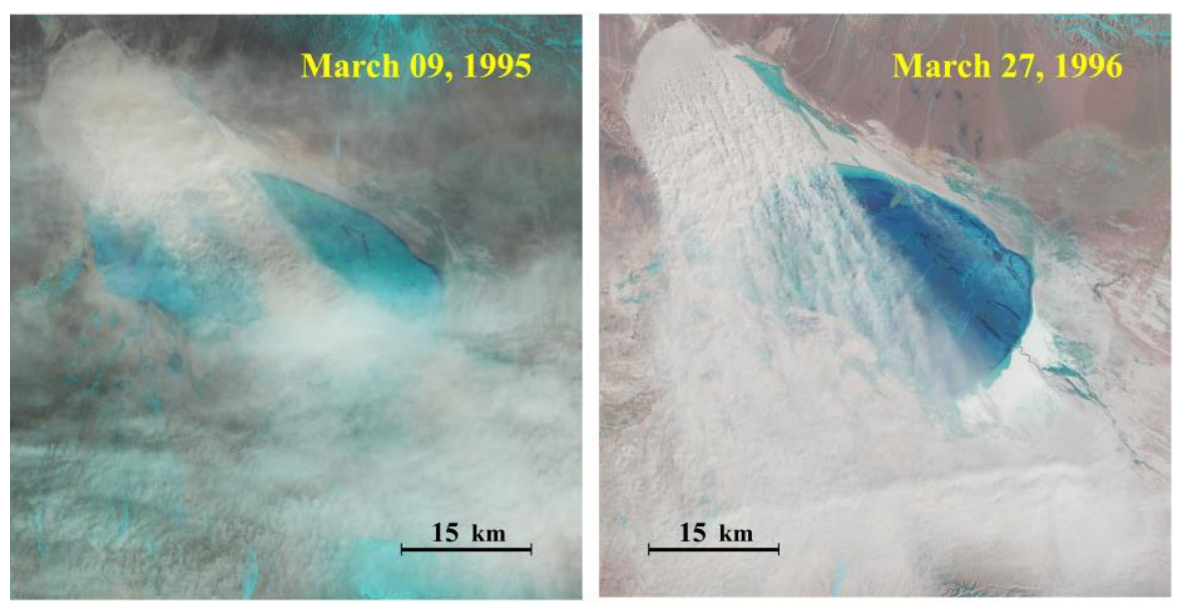

Fig.3 Salt storms. Landsat-5 images of Lake Ebi-Nur during 1995-1996 years. From GloVis (USGS) data portal

\section{Conclusion}

According to satellite monitoring (LANDSAT-8, SENTINEL-2A), water deficit during 2018-2020 years reduced the area of the seasonal minimum of the Ebi-Nur water mirror (September), to the state of a multi-year minimum. The acute lack of water in 2021 has significantly worsened the situation. The first time in its modern history, Lake Ebi-Nur has approached the state of losing most of the water mirror and turning into a salt marsh. From the south with the Lake Ebi-Nur basin is adjacent to the valley of the big transboundary (China-Kazakhstan) River Ili. This is the largest river in the Xinjiang China, with an average annual outflow at the China-Kazakhstan border is equal $12 \mathrm{~km}^{3}$. They are separated by a narrow and high ridge Boro-Horo (4359 m), belonging to the Eastern Tien Shan. A technical water pipeline with a length of 50-60 km under the Boro-Horo mountain's range can be created, which will solve the problem of stability of the water mirror area of Lake Ebi-Nur. However, the political aspects of creating such solution are very hard. 


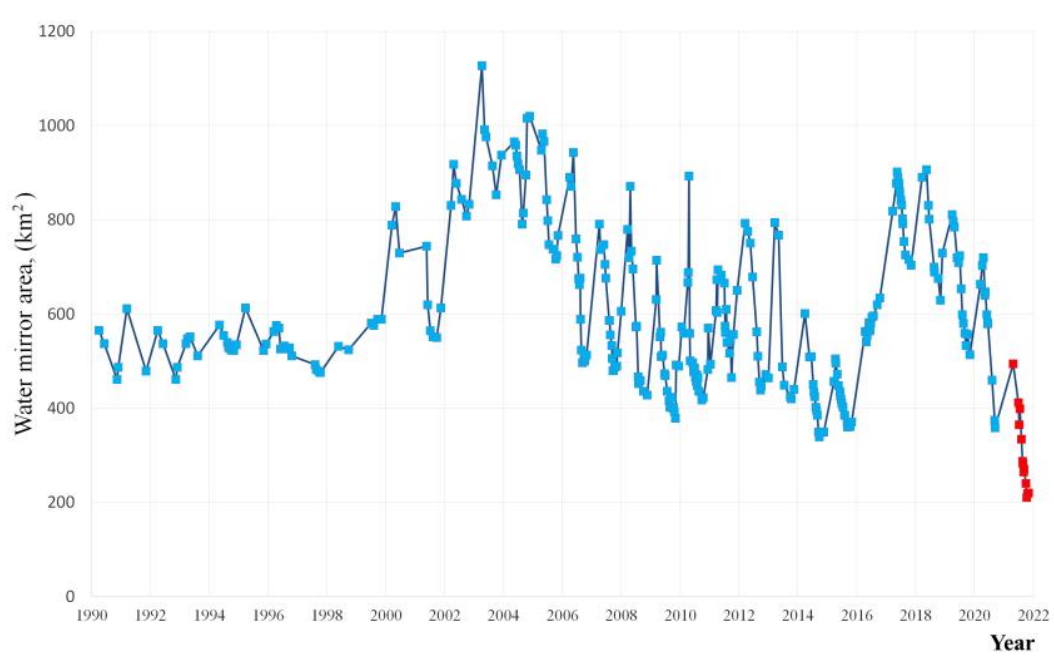

Fig. 4. Satellite monitoring of water mirror area of Ebi-Nur Lake during 1990-2021 years (Landsat 5,7,8; Sentinel-2). Red color is 2021 data. From GloVis (USGS) data portal

\section{Acknowledgment}

This research is funded by the Science Committee of the Ministry of Education and Science of the Republic of Kazakhstan (Project No. BR10965172).

\section{References}

1. A. Terekhov, N. Abayev, Sovremennye problemy distantsionnogo zondirovaniya Zemli iz kosmosa, 17, 7, 265-269, (2020), DOI: 10.21046/2070-7401-2020-17-7-265269.

2. A. Terekhov, Gidrometeorologiya i Ekologiya, 2017, 87, 4, 54-62, (2017).

3. A. Terekhov, Abst.16-th Conf. "Modern problems of remote sensing of the Earth from space", Moscow, ISR RAS, November 12-16, 117, (2018), DOI: 10.21046/207016DZZconf-2018a.

4. A. Terekhov, N. Abayev, E3S Web of Conference, 223, 02009, (2020), DOI: 10.1051/e3sconf/202022302009.

5. J. Abuduwaili, M. Gabchenko, X. Junrong, Arid. Environ 72, 10, 1843-1852, (2008), DOI: $10.1016 /$ j.jaridenv.2008.05.006.

6. A. Terekhov, I. Vitkovskaya, N. Abayev, E3S Web of Conference, 149, 03004, (2020), DOI: $10.1051 / \mathrm{e} 3$ sconf/202014903004.

7. R. Dole, Monthly Weather Review, 114, 1, 178-207, (1986), DOI: 10.1175/15200493(1986)114<0178:PAOTEN>2.0.CO;2. 